resort to it for the salration of sight, a continued experience has convinced me, and I delay the report of several cases of interest, only to be assured of the permanence of the apparent result.

\title{
OBSCURE SOURCES OF DISEASE.
}

Bx James R. Nichols, Boston.

[Communicated for the Boston Modical and Surgical Journal.]

Thene are many instances of discase brought to the notice of physicians which are excecdingly perplexing in their character, and the sources of which are very imperfectly understood. They belong to a class outside of, and distinct from, the usual forms of diseaso resulting from constitutional idiosyncrasies, or accidental causes, within the knowledge of the patient or medical attendant. The obscurity of their origin and persistency under treatment, render them peculiarly trying to the patient and the skill of those who have them in charge, and after the trial of the usual remedies without effect, the patients are sent into the country or to the sea-shore, as the case may be, with the expectation that a change of air or residence may prove beneficial.

We cannot, in a majority of cases, regard these affections as altogether imaginary, or as resulting from some casual derangement of the nervous system; they are instances of true disease, and should be studied with the view of bringing to light the hidden source from whence they originate. I am led to believe that a considerable number arise from some disturbance in the sanitary conditions of dwellings or their surroundings, and that however improbable this may seem from a superficial or even careful examination of suspected premises, a still more thorough and extended search will often result in the discovery of some agent or agents capable of producing disease.

The chemical and physical condition of water used for culinary purposes has much to do with health, and is perhaps the oftenest overlooked by the physician in searching for the cause of sickness. We must not suppose that water is only hurtful when impregnated with the salts of lead or other metals; there are different sources of contamination, which produce the most serious disturbance upon the system. Some of these are very obscure and difflicult of detection. The senses of taste and smell are not to be relied upon in examinations, as it often happens that water entirely unfit for use is devoid of all physical appearances calculated to awaken suspicion. It is clear, inodorous, palatable, and there is no apparent source from whence impurity may arise.

A fow instances which have come under my observation may serve to illustrate the viow presented, and as suggestions to those 
who are in doubt as regards the cases of patients upon their hands.

During the past summer, the writer was consulted by a gentleman residing in Roxbury, respecting the water used in his family. It was taken into the dwelling through tin pipe from a well in the im. mediate vicinity, and appeared to be perfectly pure and healthful. Analysis disclosed no salts of lead or copper, as indeed none could be expected from the unusual precautions taken to prevent contact of the water with these metals. Abundant evidence was however afforded that, through some arenue, organic matters in unusual quantities wero finding access to the water. Careful examination of the premises disclosed the fact that an outhouse on the grounds of a neighbor was so situated as to act as a receptable for house drainings, and from thence by subterianean passages the liquids flowed into the well. Some cases of illness, of long standing in the family, disappeared upon abandoning the use of the water.

A few months since a specimen of water was brought to me for chemical examination, by a gentleman of Charlestown, who stated that his wife was afflicted with protracted illness of a somewhat un. usual character. It was found to be largely impregnated with potash and the salts resulting from the decomposition of animal and vegetable debris, and the opinion expressed that some connection existed between the well and the waste fluids of the dwelling. This seemed improbable, as all these were securely carried away in a brick cemented drain, and in a direction opposite the water supply. The use of the spade, however, revealed a break in the drain at a point favorable for an inflowing into the well, and hence the source of the contamination. Rapid convalescence followed on the part of the sick wife upon obtaining water from another source.

Analysis was recently made of water from a woll in Middlesex County, which disclosed conditions quito similar to these. The owner was certain that no impurity could arise from sources suggested, but rigid and persistent investigation disclosed the fact, that the servant girl had long been in the habit of emptying the "slops" into a cavity by the kitchen door (formed by the displacement of several bricks in the pavement), where they were readily absorbed. Although the well was quite remote, the intervening space was filled with coarse sand and rubble stones, and hence the unclean li. quids found an easy passage to the twater. This proved to be the cause of illness in the family.

It is unnecessary to present other instances of a similar character on record. These serve to bring to view some of the sources of impurities in water used for household purposes, and the obscure cause of serious diseases. The location of wells connected with dwellings is a matter which should receive attention at the hands of physicians.

It is well known that in the gradual decomposition of animal and 
vegetable substances, at or near the surface of the earth, under certain conditions, nitrogenous compounds are developed. The nitre earths found bencath old buildings result from these changes, although it is quite difficult to understand the precise nature of the chernical transformations which produce them. In the waters of a large number of wells in towns and cities, and also in the country, the nitrates are found at some seasons in considerable quantitics. The salts form at the surface in warm weather, and being quito soluble, are carried with the percolating rain-water into the well. In cities and large towns, where excrementitious matters accumulate rapidly around dwellings compacted together, it is difficult to locato wells remote from danger, and hence it might seem that suspicion should be confined to these localities. This, however, is not a safe conclusion. How often do we see, upon isolated farms in the country, the well located within, or upon, the margin of the barnyard, near huge manure heaps, reeking with ammoniacal and other gases, the prolific sources of soluble salts, which find access to the water and render it unfit as a beverage for man or beast. It may no doubt be a convenience to the farmer to have his water-supply so situated as to meet the wants of the occupants of his barn and his $\mathrm{d}$ welling, but it is full of danger.

Whilst admitting that such may be the condition of the water of many wells, doubts may arise with some, whether substances not decidedly poisonous, and received in such quantities, can after all be productive of much harm, or the real source of illness. To the great majority of people they are certainly harmless, but it must be admitted that there is a class, and one or more are found in almost every family, whose peculiar sensitive organization does not admit of the presence of any extraneous agent in food or drink, or in what they iuhale. The functions of life and health are disturbed by the slightest deviation from the usual or normal condition of things around them. It is manifestly of importance that physicians should recognize these peculiarities in individuals. It is unsafe, in making a diagnosis of disease, or seeking for causes, to overlook or forget them.

We are, indeed, incapable of understanding how this can be. It seems incredible that the thousandth part of a grain of one of the salts of lead, dissolved in water and taken daily, will disturb the system of any one; and yet such is the case. Wo can see no reason why a very little nitrate of potassa, or soda, or lime, taken in the same way, should produce any effects; still stranger is it that the infinitesimal amount of dust dislodged from painted wall-papers, received into the lungs, should make inroads upon health.

Several instances of this latter result have recently come to my knowledge. In two families of the highest respectability in this city, illness of an unusual and protracted character existed, and at the suggestion of the physician, portions of the green wall-paper of 
the dwelling were submitted to me for analysis. The pigments were found to consist mainly of arseniate of copper, and upon the removal of the papers the illness disappeared. In experimenting with apparently the most suitable apparatus, and employing delicate chemical tests, in rooms the walls of which were covered with these arsenical papers, no evidence of the presence of the poison in the atmosphere has been afforded; and this corresponds with the results of all similar experiments made in this country and in Europe, so far as my knowledge extends. We must conclude that agents not recognizable by chemical tests are capable of disturbing vital processes. The evidence is very clear that in instances of illness confined to one or two members of a household, the cause may be due to some accidental disturbance with which all are equally brought in contact, but which has not the power of injuriously influencing but a part. It is also clear that these sources of disease are of such a character as easily to escape detection, and therefore any facts or experience which may servo as guides to their discovery are worthy of record.

109 Milk Strect, March, 1863.

WASTING PALSY-PARALYSIS OF BELL AND CRUVEILHIER.

THE confusion arising from the various names assigned to this form of paralysis is very great. Dr. Roberts, in his excellent monograph,* adopts the term wasting palsy, as short and convenient, and expressing its most remarkable feature; at the same time suggesting that it should be called by the name of Cruveilhier; but it would appear that that of Sir Charles Bell should, in justice, be added. As in the previous cases, the attempts to name the disease by its clinical or pathological characters, have been quite unsuccessful, the features that were used for the purpose having been proved by increased experience not to be constantly present. Thus Aran calls it "atrophie musculaire progressive," and Duchenne "atrophie musculaire avec transformation graisseuse," and Sandahl combines both characters in his name, calling it "atroplia muscularis paralysans, adiposa, progressiva," a name rather inconvenient for common use, in addition to its being inappropriate, from its being now well established that, though the muscles generally undergo fatty degeneration, there are cases in which there is no transformation into fat, and that the atrophy is not necessarily progressive.

In this Journal, and in tho Dublin Hospital Gazette, cases presenting some points of importance have been published by Dr. Reade and Dr. Banks, proving, amongst other things, that the disease is not always progressive. Dr. Reade's $\dagger$ was that of a young man, 19 years of age, who had been suffering from the discase for eighteen

- Reviewed in Dublin Quarterly Journal of Medicine, vol. xxvi., p. 101.

† Dubliu Quar. Jour. of Med., vol. xxil., p. 393. 